\title{
Is a Doctor Like a Toaster? Earning Trust in the Profession of Medicine
}

\author{
Laura Weiss Roberts ${ }^{1}$ (D)
}

Received: 18 April 2017 / Accepted: 20 April 2017 /Published online: 3 May 2017

(C) Academic Psychiatry 2017

A recent issue of Consumer Reports features a disheveled, exhausted, and unshaven physician on its cover. The physician is shown holding a nearly full martini glass, and a pill bottle in the pocket of his white coat bumps into the stethoscope around his neck. The cover also highlights ratings on washers, dryers, and lawn mowers, the risks and rewards of reverse mortgages, and assessments of Lexus RX, Lincoln MKX, and BMW 7 series automobiles. All these items, doctors, lawn mowers, mortgages, and BMWs, are proffered by Consumer Reports as newsworthy objects for public scrutiny.

"What you don't know about your doctor could hurt you," states the headline, "Botched surgeries, substance abuse, sexual misconduct - doctors on probation can still practice medicine, and they don't have to tell you." The corresponding article gives examples of the egregious behavior of explicitly named physicians. Photographs of impaired physicians and families who have lost loved ones after medical mistakes are scattered throughout. A quote from a former employee of the National Practitioner Data Bank is prominently displayed at the midpoint of the article on physician conduct: "You can find out more about the safety record of your toaster and whether or not it's going to catch fire than you can find about your physicians."

So, is a doctor like a toaster? Should a physician be rated like a manufactured product? Should the public adopt such an approach as a method of ensuring clinician competence?

In theory, no. Physicians belong to a profession that exists to serve society. Professions are given the responsibility to educate and prepare their own members, and these members

Laura Weiss Roberts

RobertsL@stanford.edu

1 Stanford University, Stanford, CA, USA are expected to work for the benefit of others by advancing knowledge and sharing their expertise. Professions have a duty to define their own standards of conduct and professions must ensure that their members adhere to these standards of conduct. The privilege of belonging to a profession should be removed when standards are not met. Consumer Reports should not need to evaluate physicians or determine the boundaries of professional competence, because physicians, as members of a profession, ought to carry these responsibilities themselves.

Why did Consumer Reports treat the physician as a "product" to be rated? Why is the status of the physician as a professional not sufficient enough to assure the trust of the public?

These questions are particularly salient in light of recent headline news that the Accreditation Council for Graduate Medical Education (ACGME) has changed duty hour restrictions, allowing resident physicians to work up to $28 \mathrm{~h}$ straight, effective July 1, 2017 [1, 2]. Resident physicians will continue to have their workweek capped at $80 \mathrm{~h}$, as they have since 2011, but the new guidelines permit physicians-in-training to work $12 \mathrm{~h}$ beyond the previous limit of 16-h shifts [2]. In communicating the new approach, the ACGME stated that, under the 2011 policy, hypothesized benefits related to patient safety and physician well-being had not been realized and that disruptions in team-based care and supervisory systems negatively affected residents' clinical training [3]. The change in ACGME rules has nevertheless drawn severe criticism from both inside and outside the medical profession and has been characterized as a "dangerous proposal" showing "reckless disregard" for patients and young physicians [4].

The public is riveted by threats to public trust in the medical profession, including medical mistakes, prescription overdose deaths, conflicts of interest, and poor access to care. Medical mistakes have been identified as the third leading cause of 
mortality in the USA - accounting for approximately $9.5 \%$ of all deaths each year [5, 6]. It is estimated that medical mistakes have, on average, led to more than one quarter of a million deaths annually since 1999, and medical mistakes have lagged behind only heart disease and cancer as a cause of mortality. To put this in perspective, medical mistakes account for about as many deaths each year as suicide $(n=42,773)$, Alzheimer's disease $(n=93,541)$, and stroke $(n=133,103)$ combined [6].

Separate from the issue of medical error, deaths attributed to overdoses of prescription medications have increased dramatically in recent years. In 2014, deaths due to prescribed medications exceeded 25,000, a 2.8-fold increase since 2001 [7]. Among these deaths, 18,893 were due to prescribed opioid pain relievers, a 3.4-fold increase since 2001 [7, 8]. Certain areas of the country, including rural communities and urban neighborhoods, and certain subpopulations, including minority, youth, and elder groups, have been hit especially hard by this lethal opioid epidemic, with profound disparities in health outcomes $[9,10]$. Psychiatrist Anna Lembke's recent book, Drug Dealer MD: How doctors were duped, patients got hooked, and why it's so hard to stop, highlights how well-intentioned physicians have contributed to the opioid epidemic [11].

An extensive and persuasive empirical literature has arisen over the past decade showing the palpable influence of pharmaceutical company advertising and incentives on medical practice $[12,13]$. In her remarkable book, The Truth about Drug Companies, Marcia Angell, former editor of the New England Journal of Medicine, documented unethical practices found in the medical industry and exposed the impact and collusion of medicine in the "medical industrial complex" [14]. Continued public scrutiny of conflict of interest between physicians and the pharmaceutical industry has been intensified by Senator Grassley's and Senator Kohl's Sunshine Act legislation, which requires that a financial exchange of $\$ 100$ or more from makers of pharmaceuticals, devices, and biologic agents to physicians and biomedical researchers be publicly disclosed [15]. Regarding the legislation, Grassley has stated that such accountability will be "good for the medical profession and the patients who rely on their care" [16].

Barriers in access to health care are widely felt throughout the USA and many other countries throughout the world [17-19]. Insufficient numbers of physicians, especially in rural and frontier areas, and high cost of professional and clinical services are clear challenges for patients seeking health care [20]. New legislation to be advanced under President Trump's administration to progressively dismantle the Affordable Care Act (ACA) is anticipated to reduce insurance coverage for many millions of Americans [21]. Centers for Disease Control and Prevention data from 2013, prior to the ACA's adoption in 2014, showed that $41 \%$ of Hispanic, $25 \%$ of African American, $16 \%$ of Asian, and $15 \%$ of white adults, aged 18-64, lacked health insurance in the USA, and many did not obtain necessary care due to cost [22].

\section{The Paradox of the Erosion of Trust in Medicine}

Observations regarding mistakes, unintended consequences, conflicts of interest, and challenges in access to care naturally lead patients and the public to the question whether sufficient safeguards are in place to ensure that physicians can and will protect their health. And yet, it is striking that issues around trust in the medical profession occur at a time when health care outcomes for serious illnesses and chronic conditions have dramatically improved. New scientific discoveries have prompted changes in clinical practices involving prevention, early identification and intervention, and surveillance. These changes have led to increased survival and enhanced quality of life in patients with infectious diseases [23]; cardiac disease [24]; lung, breast, colon, and prostate cancers [25]; diabetes [26]; and, also importantly, mental disorders [27, 28]. Looking ahead, advancing efforts to improve health outcomes and transform quality and safety standards have emerged as a foremost commitment across the entire US health care system [29]. Moreover, the engagement of medicine with new technologies in health care has already led to innovation in clinical practices and opened up opportunities for better population health [30]. These great advances suggest that the profession of medicine is vigorous and effective in its efforts to serve human health.

In addition to demonstrably beneficial health care practices, there is clear evidence of self-monitoring and regulation within the profession of medicine. Data from the National Practitioner Data Bank, for example, suggest that medical professionals are, in fact, actively engaged in self-monitoring [31]. After a peak of 20,353 malpractice cases reported in 2001, the number of malpractice cases has steadily declined while the number of other reported actions, such as adverse decisions regarding clinical privileges and membership in professional societies, has steadily increased [31]. In addition, a groundbreaking randomized trial published last year in the New England Journal of Medicine involving 4330 surgical residents in programs with more and less restrictive duty hours showed no difference in the health outcomes of the 138,691 patients for whom the residents provided care. Moreover, and unexpectedly, no difference was found to exist in the residents' perceptions of overall well-being and quality of their educational experience [32].

Despite this evidence, societal opinion remains the same. The Consumer Reports' cover story is a clear signal of the lack of trust in the medical profession, highlighting the problems of physician exhaustion, impairment, and misconduct. Unfortunately, disappointment and skepticism about physicians have been long in the making. In 1985, Cassell and Siegler observed that

...the public demands a more personal medical care governed by ethical strictures not dreamed of a decade 
ago, care in which the patient is seen as a full and knowledgeable partner. At the same time, patients are suspicious of physicians and technology even while taking the effectiveness of both for granted. The paradoxes are numerous and depressing to contemplate [33].

Reinforcing this point, in a public survey study published in the New England Journal of Medicine in 1990, more than 50\% of respondents felt that their doctors cared less about their patients than those in the past, and only $29 \%$ of patients felt that doctors had spent enough time with them [34]. One quarter of respondents respected their doctors less than they had 10 years before. These negative views were held literally decades ago and continue to be held today, despite remarkable improvements in health outcomes associated with advances in clinical care.

\section{The Practice of Psychiatry, the Values of the Profession, and the Public Trust}

Psychiatrists think a great deal about how best to establish and sustain trust. Psychiatrists bring their expertise, a blend of practical wisdom and applied science, and their authentic selves to the therapeutic relationship. By nurturing the relationship, setting aside other interests, and tending to professional boundaries, psychiatrists purposefully create a context of compassion, predictability, and safety for their patients. Especially evident in the context of psychotherapy, psychiatrists work actively and deliberately to demonstrate dedication to the health and well-being of their patients. Psychiatrists help patients to learn and feel connected. Psychiatrists seek to attain an empathic understanding of their patients; through attention and attunement, psychiatrists make it clear that the individual patient truly matters. Psychiatrists speak and behave in a manner that is congruent ("walking the talk") and that communicates respect and honesty, understanding that these actions are fundamental to human healing.

Psychiatrists, importantly, do not turn away from the anguish, fears, and experiences of their patients - aspects of their patient's inner lives that may otherwise create isolation and rupture a sense of belonging. Psychiatrists endeavor to help patients bear the burdens they carry so they may look to the future with hope. Trust is established and sustained through these intentional efforts of psychiatrists.

Can these same approaches of psychiatrists "scale up" to address the concerns of the public regarding the whole of the medical profession? Certainly these principles could be applied to improve doctor-patient relationships and encourage interpersonal trust. Public concern is not limited to the quality of doctor-patient relationships, however. This concern is widespread and often well founded, exposing deeper issues within the system of health care itself. Trust in the medicine cannot be completely restored without a comprehensive, sophisticated, and well-powered transformation of the health system. This transformation must necessitate change at every level, including health care financing, biomedical science and technological innovation, medical education, governmental agencies, and engagement with patients and society at large.

\section{Earning the Trust of the Public}

How can physicians regain a position of trust in our society? How do we differentiate the profession of medicine from manufacturers of lawn mowers, cars, and toasters, and even from the disgraced mortgage industry, in the eyes of the public?

Embracing the enduring values of the profession of medicine, in my view, is the path to being worthy of public trust. We must make every effort to demonstrate to stakeholders across society that physicians have not forgotten the nature and obligations of their profession. Physicians have been given the privilege of learning, advancing knowledge, and teaching in order to help patients and populations by preventing and curing illness, restoring health and function, and lessening the burden of suffering. Along with this privilege, physicians have an obligation to improve standards of care and to assure the competence of colleagues.

Rigorously studying the impact of our policies, such as the recent move to relax restrictions on duty hours of resident physicians by the ACGME and governmental efforts to tighten controls to prevent conflicts of interest in medicine, is critically important to reestablishing our profession's credibility. Proactive efforts to strengthen standards of care for chronic and disabling conditions and to minimize prescribing practices that lead to iatrogenic harm are also necessary. Further, learning how to recognize physicians who are struggling to fulfill their professional responsibilities and how best to intervene, for their good and the good of their patients, is a related obligation of the profession. We should not leave such monitoring activities to the editors and writers of Consumer Reports. Indeed, we must undertake these efforts ourselves, and we must also work to communicate and collaborate our societal stakeholders in a responsible, transparent manner. These steps are critical as we work individually and collectively to earn public trust.

Those physicians who show, on every occasion and in every role in life, their dedication to patient well-being will shape more positive views among those in their immediate spheres of influence. Academic physicians, through their work in science and scholarship, clinical service and innovation, education and mentorship, community outreach, leadership, and stewardship may further demonstrate the salutary contributions of the medical profession in society. Physicians who serve as policy makers, as institutional and systems leaders, and public figures may bring benefit to the health of populations and to the lives of thousands of individual patients if their communications, strategies, and operational decisions are governed by the aspirational values and fundamental ethics of medicine. All physicians, by seeking to attain greater competence, by working within their abilities, 
and by confronting with honesty the exhaustion, limitations, or impairment of colleagues, will help assure the health of those in need and offer reassurance to those observing our conduct. Such repeated demonstrations of integrity will do much in the creation of a system of care that will truly serve the public and inspire renewed confidence in the profession of medicine.

\section{Compliance with ethical standards}

Disclosure The author states that there is no conflict of interest.

\section{References}

1. Dwyer C. Rookie doctors will soon be allowed to work up to 28 hours straight. NPR. March 2017. Available at http://www.npr.org/sections/ thetwo-way/2017/03/10/519662434/rookie-doctors-will-soon-beallowed-to-work-up-to-28-hours-straight. Accessed 31 March 2017.

2. Accreditation Council for Graduate Medical Education. ACGME common program requirements, Section IV, tracked changes. 2017. Available at https://assets.fridgecms.com/81a7119e-968c-425cb67c-1cc44e028d44/CPRs_Section\%20VI_2017-07-01_TCC.pdf. Accessed 31 March 2017.

3. Nasca TJ. Common program requirements: the learning and working environment (duty hours): memo. Accreditation Council for Graduate Medical Education. 2017. Available at https:// acgmecommon.org/announcement. Accessed 31 March 2017.

4. Public Citizen. Statements from experts in response to the ACGME board's reckless vote to loosen medical resident work hour rules. 2017. Available at http://www.citizen.org/pressroom/ pressroomredirect.cfm?ID=10202. Accessed 31 March 2017.

5. Institute of Medicine. To err is human: building a safer health system. Kohn LT, Corrigan JM, Donaldson MS, eds. Washington DC: National Academy Press, 2000.

6. Makary M, Daniel M. Medical error-the third leading cause of death in the U.S. BMJ. 2016;353:i2139.

7. National Institute on Drug Abuse. Overdose death rates. 2017. Available at https://www.drugabuse.gov/related-topics/trendsstatistics/overdose-death-rates. Accessed 31 March 2017.

8. Center for Disease Control and Prevention. Drug-poisoning deaths involving opioid analgesics and heroin: United States, 2000-2013. 2015. Available at https://www.cdc.gov/nchs/products/databriefs/ db190.htm. Accessed 31 March 2017.

9. Marema T. Prescription drug-death rate grows fastest in rural. The Daily Yonder. 2016. Available at http://www.dailyyonder.com/ prescription-drug-death-rate-grows-fastest-in-rural/2016/08/09/ 14662/. Accessed 31 March 2017.

10. Substance Abuse and Mental Health Services Administration. Specific populations and prescription drug misuse and abuse. 2015. Available at http://www.samhsa.gov/prescription-drugmisuse-abuse/specific-populations. Accessed 31 March 2017.

11. Lembke A. Drug dealer, MD: how doctors were duped, patients got hooked, and why it's so hard to stop. Baltimore: Johns Hopkins University Press; 2016.

12. United States Government Accountability Office. Prescription drugs: improvements needed in FDA's oversight of direct-toconsumer advertising. 2006. Available at www.gao.gov/new. items/d0754.pdf. Accessed 31 March 2017.

13. Spurling GK, Mansfield PR, Montgomery BD, et al. Information from pharmaceutical companies and the quality quantity, and cost of physicians' prescribing: a systematic review. PLoS Med. 2010;7(10):e1000352.
14. Angell M. The truth about drug companies: how they deceive us and what to do about it. New York: Random House; 2004.

15. Physician Payments Sunshine Act of 2009, S. 111-301. 2009.

16. Grassley.Senate.gov. Grassley statement on efforts to address conflicts on interest in medicine. 2009. Available at http://www. grassley.senate.gov/news/news-releases/grassley-statement-effortsaddress-conflicts-interest-medicine. Accessed 31 March 2017.

17. Andrade LH, Alonso J, Mneimneh Z, et al. Barrier to mental health treatment: results from the WHO world mental health surveys. Psychol Med. 2014;44(6):1303-17.

18. Johnson M, Samarina A, Xi H, et al. Barrier and access to care reported by women living with HIV across 27 counties. AIDS Care. 2015;27(10):1220-30.

19. Kullgren JT, McLaughlin CG, Mitra N, Armstrong K. Nonfinancial barriers and access to care for U.S. adults. Health Serv Res. 2012;47(1 Pt 2):462-85.

20. Association of American Medical Colleges. Recent studies and reports on physician shortages in the US. Center for Workforce Studies. 2012. Available at https://www.aamc.org/download/ 100598/data/. Accessed 31 March 2017.

21. Congressional Budget Office. Cost estimate: American Health Care Act. 2017. Available at https://www.cbo.gov/system/files/115thcongress-2017-2018/costestimate/americanhealthcareact.pdf. Accessed 31 March 2017.

22. Martinez ME, Ward BW, Adams PF. Heath care access and utilization among adults aged $18-64$, by race and Hispanic origin: United States, 2013 and 2014. National Center for Health Statistics, 2015. Available at https://www.cdc.gov/nchs/data/databriefs/db208.htm. Accessed 31 March 2017.

23. Lazarus JV, Safredd-Harmon K, Barton SE, et al. Beyond viral suppression of HIV - the new quality of life frontier. BMC Med. 2016;14:94.

24. American Heart Association. Progress against heart disease, stroke reflected in latest statistics., 2014. Available at http://news.heart. org/progress-against-heart-disease-stroke-reflected-in-lateststatistics/. Accessed 31 March 2017.

25. National Cancer Institute/ Cancer trends progress report. NIH, DHHS, 2015. Available at http://progressreport.cancer.gov. Accessed 31 March 2017.

26. Tucker ME. Landmarks in diabetes: 1995 to 2015. Medscape Diabetes \& Endocrinology, 2015. Available at http://www. medscape.com/viewarticle/845125. Accessed 31 March 2017.

27. Birur B, Moore NC, Davis LL. An evidence-based review of early intervention and prevention of posttraumatic stress disorder. Community Ment Health J. 2017;53(2):183-201.

28. Marwaha S, Thompson A, Upthegrove R, Broome MR. Fifteen years on-early intervention for a new generation. Br J Psychiatry. 2016;209:186-8.

29. Agency for Healthcare Research and Quality: A profile. DHHS, 2016. Available at http://www.ahrq.gov/cpi/about/profile/index. html. Accessed 31 March 2017.

30. Morrissey J. The medical technologies that are changing health care. Hospitals and Health Network, 2015. Available at http:// www.hhnmag.com/articles/3580-the-medical-technologies-thatare-changing-health-care. Accessed 31 March 2017.

31. U.S. Department of Health and Human Services. National practitioner data bank, 2012 annual report. 2014. Available at https:// www.npdb.hrsa.gov/resources/reports/2012NPDBAnnualReport. pdf. Accessed 31 March 2017.

32. Bilimoria KY, Chung JW, Hedges LV, et al. National clusterrandomized trial of duty-hour flexibility in surgical training. N Engl J Med. 2016:374:713-27.

33. Cassell EJ, Siegler M, eds. Changing values in medicine. Fredericks, M.D.: University Publications of America, 1985: 2.

34. Blendon RJ, Donelan K. The public and the emerging debate over national health care insurance. N Engl J Med. 1990;323:208-12. 